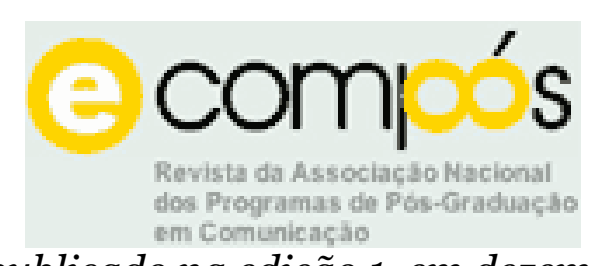

Este artigo foi publicado na edição 1, em dezembro de 2004, da revista eletrônica e-compós: http://www.compos.org.br/e-compos

\title{
A CIDADE COMO ARENA DA MULTICULTURALIDADE
}

\section{Renato Cordeiro Gomes ${ }^{1}$ PUC-Rio / CNPq}

As teorias que vêm formulando a construção da cidade digital, ou cibercidade, (Castells, Martín-Barbero, Aurigi \& Graham, Lemos etc) insistem em que esta não deve ser encarada como uma simples substituição da cidade real, em que se constatam a erosão do espaço público e a apatia social, a atrofia da experiência plena (já teorizada por Walter Benjamin com a implantação do projeto moderno). Esse projeto moderno para as cidades (a cidade é um dos tópicos incontornáveis desse projeto, ou melhor, é o próprio projeto) sempre esteve conjugado às novas tecnologias, que modificam radicalmente a percepção e a sensibilidade humanas e alteram o imaginário e a subjetividade, na linha demonstrada por Georg Simmel, no ensaio “A metrópole e a vida mental”, de 1902. Há mesmo uma reorientação simbólica que se tornou possível pela disjunção entre

\footnotetext{
1 Doutor em Letras pela Pontifícia Universidade Católica do Rio de Janeiro, onde é professor Associado do Departamento de Comunicação Social. Pesquisador do CNPq. Coordenador do Programa de Pós-Graduação em Comunicação da PUC-Rio. Coordenador-Adjunto da Cátedra Padre António Vieira de Estudos Portugueses da PUC-Rio em convênio com o Instituto Camões.

Publicações: Todas as cidades, a cidade (Rio de Janeiro: Rocco, 1994); João do Rio: vielas do vício, ruas da graça (Rio de Janeiro: Relume-Dumará, 1996); organizou o volume Marques Rebelo da Coleção Melhores Crônicas (São Paulo: Global, 2004). Entre seus últimos ensaios publicados, destacam-se: De superfícies e montagens: um caso entre o cinema e a literatura", in Literatura e mídia, org. Karl Eric Schollhammer e Heidrun Krieger Olinto (2001); "A cidade como livro", in SUSSEKIND, F. \& DIAS, T. A historiografia literária e as técnicas de escrita: Do manuscrito ao hipertexto (Rio de Janeiro: Casa de Rui Barbosa, 2004);
} 
a base religiosa de um mundo longamente estável e a irrupção desestabilizadora das novas tecnologias, assentadas sobre a aceleração, a fragmentação e a concentração isoladas das grandes cidades (Sevcenko, 1994, p.212).

Embora se observe a crise das megalópoles contemporâneas, num processo que remonta ao nascimento da modernidade industrial que levou a corroer o projeto da "cidade da virtude racional" como fator civilizacional (Schorske), gerando a "cidade dos vícios sociais" (como resultado da Revolução Industrial: as desigualdades sociais, a exclusão da cidadania, a violência, enfim, a cidade doente), é fato corrente que o mundo se tornou urbano. “As cibercidades nascem neste terreno de fragmentação, isolamento e guetificação, tanto dos espaços, como das relações sociais que aí se manifestam” (Aurigi \& Graham, 1998, p. 57, apud Lemos).

Talvez este estado de coisa tenha a ver com o que o arquiteto e historiador argentino Adrián Gorelik revela sobre as relações entre modernidade e modernização em seu ciclo expansivo, guiado pelo Estado, que acaba levando à enfermidade: a cidade doente. O conflito entre modernidade e modernização (ele enfatiza o caso da América Latina) se mostra como contraface necessária da ampliação da arena política que abre a nova cidade, aquela que passa pelo processo de reforma, ou de construção radical (Brasília, por exemplo), em nome do progresso, da mudança enquanto fundamento da própria modernidade. Assim, sob o signo da planificação se gesta o espaço público da expansão, e sobre ele, o ideal de uma relação orgânica entre modernidade e modernização, entre determinados tipos de espaço público e modalidades de cidadania.

Os anos de 1960 assistiram à reação contra a planificação modernista, levando a rever os fundamentos urbanísticos do modernismo e apontando para o final do ciclo expansionista. "Dá-se o regresso à cidade considerada em suas qualidades existentes, históricas ou contemporâneas. O intenso apelo à história nas novas propostas poderia ser visto como uma maneira de reconhecer a heterogeneidade e a dispersão provocada pelo fim do ciclo 'progressista'. A história - como na obra de Aldo Rossi - procurava funcionar na produção de um imaginário sobre a cidade como o projeto na urbanística modernista: como argamassa, como concentração das partes, como guia para reconduzir uma totalidade cuja promessa de integração já não se podia buscar no futuro, mas no 
passado. Mas por isso supunha, por sua vez, um regresso à cidade, àquela parte da cidade negada pelo modernismo: os valores da cidade tradicional como núcleo de sentido para o redesenho da cidade moderna” (Gorelik, 1999, p. 71). Propunha-se por outro lado o caminho d recuperação do espaço público, como instrumento de revitalização da sociabilidade urbana nos velhos centros abandonados e deteriorados, ou a reivindicação do popular urbano através da recuperação estética dos produtos da indústria cultural de massa, tão depreciados pela alta elaboração formal modernista já institucionaliza no pós-guerra. (Gorelik, p. 71). Conseqüentemente, no que se chamou de pós-moderno, constata-se a "revalorização cultural da cidade" na década de 1990, na América Latina. Sublinha, entretanto, que "cortado o fluxo contínuo do tempo progressista, com a queda da tensão modernista que outorgava um sentido e um projeto à heterogeneidade material da cidade, a paisagem urbana aparece como uma justaposição de artefatos efêmeros (....) e, de repente, como enclaves auto-suficientes, incrustações radiantes de novidade técnica ou social, com a trama invisível mas onipresente dos meios eletrônicos configurando novos percursos, novas fruições; a cidade é assim definitivamente um patchwork no qual cada fragmento libera seu sentido, mas nessa liberdade não predomina a "diferença", mas o contraste e a desigualdade. Essa é a modernização atual, pós-expansiva, cuja mescla de tempos replica a leitura da cidade como ruína da modernidade”. (p. 77)

Crítico desse processo, Gorelik propõe repensar as chaves do ciclo expansivo, para voltar a discutir o sentido de revalorização da cidade em termos culturais e políticos, para além do que é ditado pela economia de mercado como ideologia única.

Um traço, porém, é indiscutível no pensamento de Gorelik: a revalorização da cidade e a questão cultural, que passam a ponto relevante da pauta desse início do século XXI, ainda que equacionadas de perspectivas diferentes.

De certa maneira, tangenciam a formulação de Gorelik as propostas do encontro patrocinado pela ONU, em Istambul, junho de 1996, para discutir os problemas das grandes cidades no mundo inteiro. "Habitat 2" foi a segunda reunião internacional convocada com esse objetivo. Esse fórum de debates procurava equacionar as questões que as megalópoles vêm criando para seus 
habitantes. Os imensos conglomerados urbanos com o crescimento populacional antes não imaginado apresentam condições de vida, em geral, deprimentes: a poluição, os engarrafamentos de trânsito, a precariedade dos transportes públicos, os problemas de saneamento básico, de moradia (cresce o número de sem-tetos: pelos dados da ONU há, nos países do Terceiro Mundo, 95 milhões de jovens e crianças morando nas ruas), a mobilidade dos migrantes que continuam afluindo em massa para os centros urbanos, ansiando por exercerem seu "direito à cidade" (a expressão é de Henri Lefebvre, 1969), todas as modalidades de nomadismo. Processa-se, por outro lado, no espaço concentrado das grandes cidades, o dramático contraste da sociedade, de suas tensões e de seus conflitos: a extrema pobreza e a extrema riqueza. Com o contingente de excluídos, crescem a cultura do medo e os índices de violência (Konder, 1996, p. 7). Essas foram algumas das questões da pauta da Habitat 2, que não poderia esquecer o componente cultural, ao constatar o multiculturalismo das grandes cidades, que não são mais homogêneas. A reunião de Istambul confirmou não estar mais a questão da cidade circunscrita à esfera nacional; ao contrário, requer soluções globalizadas, num momento em que cerca de 80\% do mundo é urbano.

Outro evento, agora no âmbito das artes, é mais um índice forte do privilégio dado à cidade nos anos 90. Refiro-me à belíssima exposição realizada no Centro Georges Pompidou, em Paris, em 1994: La ville: art et architecture en Europe 1870-1993. Divida em duas seções: "A cidade dos artistas" e "A cidade dos arquitetos", a mega-exposição, secundada por outra menor que versava sobre os escritos urbanos de Walter Benjamim, veio confirmar ser o destino da cidade o principal empreendimento de nosso tempo. A exposição pretendeu alimentar esse grande debate do fim do século XX, reunindo obras de artistas que, de 1870 a 1993, testemunharam a cidade. $O$ evento não só misturou o fato social com o estético, mas também considerou inseparável a história da cidade e a história da arte, sem esquecer o papel que os artistas desempenharam na invenção da cultura moderna das cidades, contribuindo para a construção do imaginário urbano - seu museu imaginário - ou, dito de outro modo, o próprio imaginário da modernidade (Dethier, 1994, p. 16). Interrogar o pensamento sobre a cidade no século XX não é apenas fazer um levantamento dos lugares; é antes querer alertar sobre sua atual 
condição, para a qual não há mais uma doutrina coerente para garantir a harmonia da vida da cidade. A teoria do urbano tornou-se praticamente impossível, a cada instante ultrapassada pelo quantitativo e pelas tecnologias eletrônicas e digitais. A cidade é o espetáculo da civilização em sua história e sua atualidade; seu solo é o espelho que registra nossas ações - afirma Alain Guiheux, um dos curadores da mostra em Paris. A exposição veio afinal mostrar que a visão totalizante da cidade torna-se impossível, mas denota, antes, uma urgência, na medida em que a "cidade determina nosso cotidiano e dá forma aos nossos quadros de vida; ela é tanto nosso presente turbulento como nossos velhos medos”- afirma François Barré, no "Préface” (1994, p. 12), do magnífico catálogo. Para enfrentar tais questões, a exposição utilizou todos as mídias e convocou todas as disciplinas, completa o prefaciador.

A exposição de Paris veio confirmar que a cidade se vincula, numa relação de dupla implicação, à modernidade. Ponto de pauta das vanguardas, continua sendo uma preocupação pós-moderna. Revelou, mais uma vez, que a cidade é uma obsessão inevitável, que se intensifica em vez de esmorecer, como sublinha Teixeira Coelho ao comentar a 25 ${ }^{\mathrm{a}}$ Bienal de São Paulo (2002: 46). Um dos seus dois módulos, intitulado justamente Iconografias Metropolitanas, busca discutir os efeitos, as potências, as reverberações da vida nas grandes cidades na produção dos artistas. Neste sentido, é válido o comentário de Katia Canton, na revista Bravo! (março 2002): "Esse é um tema extremamente atual que leva consigo uma ressonância de outras questões centrais na vida cotidiana, como a violência e sua banalização, o anonimato gerado pelas grandes massas de pessoas, os excessos de informação que assolam a mídia e que provocam um estado de perda da memória, de semi-amnésia na população, a globalização em seus efeitos de perda de referência de si e das culturas ou, ao contrário, um acirramento da noção de local, de diferente, que tem causado um oceano cada vez mais espantoso e assustador de guerras e conflitos étnicos. A idéia de metrópole carrega consigo uma fragmentação e uma mudança aguda no conceito de identidade (e de alteridade), deslocando as noções de tempo e de espaço” (2002: 50). O módulo Iconografias Metropolitanas, que reuniu 12 mostras, correspondentes a 11 cidades reais de vários continentes e a uma cidade imaginária, empregou os mais diversos meios, suportes, linguagens, 
encarregados de tematizar tais questões contemporâneas. Essa heterogeneidade (dada por um critério, em princípio, geográfico, ou seja, a distribuição das cidades por continentes) permite evidenciar a relação entre homem, sociedade, natureza, ética, estética e tecnologias eletrônicas e digitais de comunicação.

Em linha homóloga, podemos também evocar outra exposição, realizada no início de 2003, no Centro de Arquitetura e Urbanismo, no Rio de Janeiro, que reuniu vinte e quatro projetos de renomados arquitetos franceses, intitulada Paisagens da Mobilidade, cuja proposta era acompanhar, apresentando alternativas, o dinamismo das cidades contemporâneas. Em declaração ao Jornal do Brasil (02/01/03), o curador da exposição, Francis Lambert, afirmou: "uma arquitetura que cria o deslocamento e o desenraizamento. Falar da mobilidade significa interrogar sobre as mudanças da cidade e da sociedade contemporânea, refletir sobre as múltiplas velocidades que marcam o ritmo de nossa vida moderna”. São paisagens móveis, paisagens pertencentes à mobilidade que se intensifica nos fluxos comunicacionais, apontando a cidade tanto como resposta ao acelerado avanço da revolução tecno-científica (seu impacto que altera hábitos e costumes, o ritmo e a intensidade dos transportes, a comunicação e o trabalho), como, hoje, é outra resposta ao avanço da tecnologia eletrônica e digital (que se modifica num moto contínuo). A cidade é obrigada a se redefinir. Há uma "requalificação" da cidade contemporânea, que pode ser desenhada a partir dos valores virtuais, ou seja, de uma gama de atividades que deixam de ser realizadas apenas no plano material, que significa a adaptação à inserção do ser humano no meio vitual, como sublinhou José Luiz Favaro, curador da exposição "Morar na metrópole”: o olhar de 15 arquitetos, na Bienal de Arquitetura, São Paulo 2003.

Essas alusões, aqui, elencadas servem para confirmar o interesse pelas cidades nesta última década. Algumas hipóteses, que diferem das posições de Gorelik, para tal interesse vêm sendo levantadas por estudiosos das mais diversas áreas do conhecimento. Uns, como o antropólogo Nestor García Canclini, acreditam que as cidades voltam a pensar em si mesmas, devido à crise dos grandes paradigmas ideológicos que leva os estudiosos a buscar unidades de análise mais próximas, unidades que, como a cidade, são dotadas de densidade histórica (1997, p. 141, 148) - aspecto que se atrela diretamente aos paradoxos da globalização, ou 
seja, a intensificação da interdependência transnacional e das interações globais, que faz com que as relações sociais pareçam mais desterritorializadas, e, por outro lado, o desabochar de identidades regionais e locais alicerçadas numa revitalização do direito às raízes (Santos,1995, p. 17-22). Em outras palavras, frente à globalização, dá-se a afirmação do local identificado à cidade, a realidade mais próxima. A desterritorialização gera, assim, fortes tendências para a reterritorialização (essa tensão/contradição é fartamente constatável em produtos da cultura midiática), representadas por movimentos sociais que afirmam o local, ou ainda por processos da comunicação de massa, engendrando diferenças e formas locais de arraigamento, assegura Canclini (1997, p.48). Nesse mesmo sentido, verifica-se que uma reestruturação supranacional das políticas culturais necessita combinar-se com uma nova visão das culturas étnicas e regionais, que não desapareceram no processo de globalização.

Se, como acrescenta Canclini, o espaço urbano é o lugar privilegiado de intercâmbio material e simbólico do habitante citadino, também se verifica aí uma distribuição desigual desse capital simbólico, parte da agudização das contradições e desigualdades internas das cidades.

Depois da crise dos anos 70 e 80 (o fim do ciclo de expansão progressista apontado por Gorelik), parece haver, em certas cidades, a reversão da decadência, com a recuperação do papel das cidades. Dá-se o que o italiano Aldo Bonini chamou de "renascimento das cidades", em que ganha força a dimensão cultural. Esse fenômeno atrela-se ainda à passagem da cidade à megacidade, da cultura urbana à multiculturalidade: a coexistência de múltiplas culturas urbanas no espaço que chamamos todavia urbano. Certamente, não se pergunta mais que é o específico da cultura urbana, pois se há mais de uma cidade na cidade, há uma complexidade multicultural, que antes não se considerava de maneira forte, uma vez que a preocupação era a construção de uma unidade nacional, como rvela Canclini no ensaio "Ciudades multiculturales y contradiciones de la modernidad” (1997, p. 64-104). Assim, a cidade - como sublinha Michel de Certeau - é "o teatro de uma guerra de relatos", concretizando a "arena" da multiculturalidade, o que se pode entender tanto como a multiplicidade de vozes que formam a cidade polifônica (como Massimo Canevaci, em relação a São Paulo), bem como a 
heterogeneidade cultural, sem dúvida tensa, que é atravessada pelas clivagens de etnia, sexo, gênero, classe, idade; guerra de relatos que pode ainda abranger a ação dos grandes relatos da TV e da publicidade que esmagam ou atomizam os pequenos relatos de rua ou de bairro.

Essa multiculturalidade e essa guerra de relatos são coadjuvadas pela própria geografia da cidade que sofreu modificações produzidas mais pela dinâmica da comunicação e pelos circuitos financeiros que pelas indústrias localizadas nos cinturões urbanos. Assim, mudam-se os usos do espaço urbano ao passar das cidades centralizadas às cidades multifocais, policêntricas, onde se desenvolvem novos centros. Há necessidade, portanto, de o habitante re-situar-se nessa cidade disseminada, de que cada vez temos menos idéia onde começa, onde termina, em que lugar estamos (além da cidade é ainda a cidade - como se constata em As cidades invisíveis, de Italo Calvino). Tem-se, desta forma, baixa experiência do conjunto da megalópole; nos usos da cidade e nos imaginários, perdeu-se a experiência do conjunto: atores tradicionais parecem ocupar-se de pequenos fragmentos (Canclini, 1997, p. 82).

Pela nova geografia urbana, a cidade não é mais o território delimitado, percebido como próprio dessa cidade. Muda-se a própria concepção de urbano, que se relaciona aos movimentos de comunicação, à economia internacionalizada, palcos que se comunicam entre si - o que leva a redesenhar-se o estudo das culturas urbanas, em que se leva em conta não só a definição sociodemográfica e espacial da cidade, mas a definição sociocomunicacional (Canclini, 1997, p. 86).

Outra hipótese para as preocupações contemporâneas que privilegiam a cidade é, como um corolário do dito há pouco, a simbiose entre cidade e cultura, cada vez mais flagrante nos estudos culturais, que vêem o espaço da cidade como o texto cultural mais significativo para os artistas e produtores de cultura hoje, e apontam para as inúmeras possibilidades do imenso laboratório em que se transformou o espaço da cidade entendida como esfera pública e como arena cultural.

Certamente se fala, desde algum tempo, mais em cidade do que de nação o que expressa uma certa descentralização da cena cultural que passa agora a privilegiar a auto-afirmação de expressões multiculturais. É o cenário da cidade, e 
não o da nação, que passa a ser, como mostra Antonio Augusto Arantes (1994), o espaço privilegiado para as identificações culturais emergentes, para as articulações das diversas representações sociais, ou, para usar um termo em alta, para a 'etnificação da cultura'. Um fenômeno fundamentalmente urbano, que gera, por sua vez, uma guerra de lugares (Arantes, 1994).

Nesses estudos culturais que destacam a cidade, é fecundo levar também em conta os imaginários urbanos coletivos que desempenham relevante papel na formação das identidades. Como afirma Canclini: "Este tipo de aproximação tem conseqüências para a construção da cidadania cultural, porque esta cidadania não se organiza somente sobre princípios políticos, segundo a participação 'real' em estruturas jurídicas ou sociais, mas também a partir de uma cultura formada nos atos e interações cotidianos, e em projeção imaginária desses atos em mapas mentais da vida urbana" (1997, p. 96). A cidade pode também ser encarada como uma comunidade imaginada, no sentido dado por Benedict Anderson: é um artefato cultural, não um objeto natural, embora essa noção seja minada pelo multi-racial, pela economia transnacional e pelo fato de o Estado-nação passar a ser coextensivo com a humanidade. Associa-se a tal noção, portanto, para além das fixações fundamentalistas da identidade desistoricizadas e essencialistas, o multiculturalismo, que ressalta o caráter polifônico, imaginário e híbrido daquelas identidades. "A identidade surge, na atual concepção das ciências sociais, não como ume essência intemporal que se manifesta, mas como uma construção imaginária que se narra. A globalização dominui a importância dos acontecimentos fundadores e dos territórios que sustentatavam a ilusão de identidades a-históricas e ensimesmadas" - afirma Canclini (1995, p. 124). E completa: "Os referentes de identidade se formam, agora, mais que nas artes, na literatura e no folclore - que durante séculos produziram os signos de distinção das nações -, em relação com os repertórios textuais e iconográficos gerados pelos meios eletrônicos de comunicação e com a globalização da vida urbana” (1995, p. 124). É neste sentido que ele aponta como tarefa relevante dos estudos culturais busca "entender como as indústrias culturais e a massificação urbana se articulam para preservar culturas locais e, ao mesmo tempo, fomentar uma maior abertura e transnacionalização dessas culturas" (1995, p. 123-124). Na cidade como arena do multiculturalismo, 
dão-se os embates advindos da coexistência tensa entre o local e o global, em que novas características temporais e espaciais resultam na compressão de distâncias e de escalas temporais, o que pode se abrir para uma nova modalidade de cosmopolitismo, sem referência ao Estado-nação, mas ligado à economia globalizada, à desnacionalização.

A linha de raciocínio que articula as idéias aqui exposta, vem procurando ressaltar as relações entre comunicação e cultura (multiculturalidade), no contexto da globalização, em que novos modos de simbolização e ritualização do laço social se entrelaçam às redes comunicacionais e aos fluxos informacionais (MartínBarbero, 2001 e 2004); em que as formas e forças de identidade são menos sociais e mais culturais (Touraine, 1994). A cidade, então, como arena da multiculturalidade está articulada com a nova cultura comunicacional, ou é também engendrada por ela, através da mediação tecnológica. Em tal contexto a circulação prevalece sobre a produção, que também define o padrão geográfico, já que é mais densa, mais extensa, e detém o comando das mudanças de valor do espaço (estou aqui glosando Martín-Barbero, 2004).

Segundo as perspectivas de Martín-Barbero, “as redes põem em circulação fluxos de informação e movimentos de integração à globalidade econômica, a produção de um novo tipo de espaço reticulado que debilita as fronteiras do nacional e do local ao mesmo tempo em que converte esses territórios em pontos de acesso e transmissão, de ativação e transformação de comunicar e de poder" (2004, p. 260). A nova significação do mundo, portanto, não é derivável do Estadonação.

Tais questões permitem rever as tensões entre o nacional e o cosmopolita, entre a cultura local e a cultura mundial. Cabe então perguntar se, na reflexão sobre o lugar e a forma de produção do conhecimento contemporâneo, há um sentido único quando se refere a "cosmopolitismo". Certamente, não é à toa que a introdução assinada por Carol A. Breckenridge, Sheldon Pollock, Hommi K. Bhabha e Dipesh Chakrabarty da coletânea Cosmopolitanism por eles editada, intitule-se exatamente "Cosmopolitanisms" (no plural) e afirmarem que "especificar positivamente e definitivamente cosmopolitismo é uma coisa não cosmopolita" (2002: 1). É para eles uma categoria histórica que deveria ser 
considerada inteiramente aberta e não um conceito determinado a priori pela definição de uma sociedade ou de um discurso particular. Impõe-se, então, - é a lição da referida coletânea com ensaios de intelectuais de várias procedências repensar o conceito dos diversificados cosmopolitismos, num solo histórico, a partir dos dias atuais, em que se declara o fim da soberania do Estado-nação. Neste momento pós-moderno e pós-colonial, o cosmopolitismo não pode mais ser articulado a partir de um único ponto de vista, uma mono-lógica. É necessário levar em consideração a diversidade e o discurso dos que estão à margem.

É justamente neste contexto que Walter Mignolo, no ensaio "The many faces of cosmo-polis: border thinking and critical cosmopolitanism" (editado no referido livro), procura delinear o projeto de um "cosmopolitismo crítico" e dialógico como alternativa para atender às questões do momento atual, que ele denomina pósmoderno/ pós-colonial. Para tal, procede a um percurso histórico por diferentes momentos em que o conceito teve fundamentação teórica que se refletia em práticas políticas e culturais.

A proposta do crítico argentino, professor da Duke University, estabelece como pressuposto a distinção entre globalização e cosmopolitismo, respectivamente, um conjunto de dispositivos para organizar o mundo com o propósito de controlar e homogeneizar, e um conjunto de projetos de convivência mundial, complementares ou dissidentes em relação aos dispositivos globais. Pode haver, então, cosmopolitismo gerencial (que reitera os dispositivos globais) ou cosmopolitismo emancipatório (divergentes). Tais considerações levam Mignolo a analisar o processo histórico dos projetos cosmopolitas a partir do século XVI, ou seja, a partir da emergência do comércio atlântico, com o advento do projeto de colonização européia do Novo Mundo, no momento em que se produz o desenho global/moderno, necessariamente atado ao colonialismo, dado indispensável para se pensar o cosmopolitismo até nossos dias, pois é nesse imaginário que continuamos a viver e é em relação a ele que se deve refletir sobre os projetos cosmopolitas do passado e sobre o futuro cosmopolitismo crítico.

Ao observar a ordem mundial contemporânea, Mignolo constata que quanto mais o capitalismo avança, mais conflitos raciais e religiosos emergem como empecilho para a possibilidade de uma sociedade cosmopolita. Por isso, é preciso 
dissolver o relativismo cultural e enfocar o poder do colonialismo e a diferença gerada por ele, por sua vez reproduzida e mantida pelos desenhos globais. O professor da Duke University propõe então a alternativa de um cosmopolitismo crítico e dialógico como essencial a um mundo trans e pós-nacional. Enquanto os outros projetos que ele historia foram pensados de dentro da modernidade, o cosmopolitismo crítico fala de um exterior, de um mundo não mais regulado por leis nacionais e emerge de diferenças locais, e não de um único centro controlador. Não se trata de uma vontade de compreensão e inclusão de culturas diferentes, mas da inserção dessas culturas como participantes do processo cultural. Desse ponto de vista, ressalta ele o papel fundamental da margem. A palavra que representa o pensamento marginal é condição necessária para o cosmopolitismo crítico e dialógico em direção à “diversalidade” (diversidade como um projeto universal), como denomina Mignolo. Diversalidade essa que não pode ser reduzida a uma nova forma de relativismo cultural, pois não se trata de aceitar que há culturas distintas. Ao contrário, ela expressa novos projetos éticos, políticos e culturais, a partir de perspectivas marginais.

O deslocamento da voz está atrelado ao que Mignolo denomina "momento pós-colonial do mundo moderno/colonial”, em que se dissolvem as fronteiras da nação, abrindo-se para um mundo transnacional. Esse tipo de cosmopolitismo está menos conjugado ao engrandecimento do Estado ou do Império do que à representação de comunidades minoritárias. Pode-se dizer que o projeto cosmopolita atual não se aloca mais no mito da nação e do cidadão do mundo, nem emerge das idéias de universalidade e progresso, mas representa o espírito de uma comunidade cosmopolita de refugiados, migrantes, exilados.

É nesse sentido que Silviano Santiago busca ultrapassar a base das tensões entre as exigências localistas e o cosmopolitismo identificado com a cultura européia, de cunho etnocêntrico, portanto, para propor um "cosmopolitismo do pobre”. Elegendo como ponto de partida o filme Viagem ao começo do mundo (1997), do português Manuel de Oliveira, Santiago mostra como está surgindo uma nova forma de "desigualdade social que não pode ser compreendida no âmbito legal de um Estado-nação, nem pelas relações oficiais entre governos nacionais, já que a razão econômica que os convoca para a metrópole pós-moderna é 
transnacional e é também clandestina" (2002: 7). Se há uma nova forma de multiculturalismo que só pode ser compreendido num processo de “desnacionalização do espaço urbano" e "desnacionalização da política” (Saskia Sassen), e se há os trânsitos de desprivilegiados do mundo, uma nova forma de cosmopolitismo emerge desse influxo de imigrantes pobres nas metrópoles pósmodernas, da mesma maneira que resgata grupos étnicos e sociais economicamente desfavorecidos no processo de multiculturalismo a serviço do Estado-nação. Esse novo cosmopolitismo do pobre conta com o apoio de movimentos políticos transnacionais, em especial pelas ONGs, que defendem os direitos das minorias e com dispositivos de comunicação e das mídias possibilitados pelas novas tecnologias, cujas redes ensejam as conexões com o sistema mundo (cf. o MST e o movimento Zapatista que estão conectados com o mundo via Internet). Novas formas de cosmopolitismo permitem, portanto, expressar novos projetos políticos, éticos e culturais, a partir de perspectivas marginais, ou seja, do deslocamento de centros hegemônicos que marcaram a tradição cosmopolita.

Talvez essa cosmópolis possa ser associada à cidade global, que, segundo Castells, não é um lugar, mas um processo, pelo qual centros de produção e consumo de serviços avançados, e as sociedades locais subordinadas a ele, é conectado em uma cadeia global, na base de fluxos de informação (Castells, 1996, p. 386). Talvez pudesse ser considerada uma nova forma de utopia, ou de resíduos utópicos de uma era pós-utópica, capaz de potencializar uma espécie de nova ágora virtual, lugar de práticas políticas que se tornaram cada vez mais rarefeitas na modernidade ocidental, devolvendo à cidade a philia, que segundo Anne Cocquelin, é a precípua função da polis.

\section{REFERÊNCIAS BIBLIOGRÁFICAS}

ARANTES, Antônio. A guerra dos lugares. Revista do Patrimônio Histórico e Artístico Nacional, ${ }^{\circ}$ 23, 1994, p. 190-203.

AURIGI, Alessandro \& GRAHAM, Stephen. The Crisis in the Urban PUBLIC Realm, in LOADER, B. D. (ed.). Cyberspace Divide: Equally, Agency and Policy in the Information Society. London: Routledge, 1998.

BARRÉ, François. "Préface". LA VILLE: art et architecture en Europe - 1870-1993. Dir. Jean Dethier \& Alain Guiheux. Paris: Centre Pompidou, 1994. 
BRECKENRIDGE, Carol A, POLLOCK, Sheldon, BHABHA, Hommi K., CHAKRABARTY, Dipesh. "Cosmopolitanisms". In: Duke University Press, 2002. (ed.). Cosmopolitanism. Durham \& London,

CANCLINI, Nestor García. Consumidores \&cidadãos: conflitos multiculturais da globalização. Rio de Janeiro: ED. UFRJ, 1995.

CANCLINI, Néstor García. Imaginarios urbanos. Buenos Aires: Editorial Universitaria de Buenos Aires, 1997.

CANEVACI, Massimo. A cidade polifônica: ensaio sobre a antropologia da comunicação urbana. São Paulo: Studio Nobel, 1993.

CANTON, Katia. “As nuances da cidade”. Revista Bravo!, março 2002, ano 5, no 54, pp.

49-51.

CASTELLS, Manuel. The Rise of the Network Society. Vol. I: The Information Age: Economy, Society and Culture. Oxford: Blackwell, 1996.

CERTEAU, Michel de, GIARD, Luce a MAYOL, Pierre. "Os fantasmas da cidade". In: $A$ invenção do cotidiano 2: morar, cozinhar. Petrópolis: Vozes, 1997.

COELHO, Teixeira. "Arte na metrópole”. Revista Bravo!, março 2002, ano 5, no 54, pp. 45-

48.

COQUELIN, Anne. Essais de prilosophie urbaine. Paris: PUF, 1982.

DETHIER, Jean. Por un musée imaginaire de la ville, in: e GUIHEUX, A. (dir.). La ville: art et architecture en Europe - 1870-1993. Paris: Centre Georges Pompidou, 1994. GORELIK, Adrián. O moderno em debate: cidade, modernidade, modernização, in MIRANDA, Wander Melo (org.). Narrativas da modernidade. Belo Horizonte: Autêntica, 1999.

GUIHEUX, Alain. Tract pour une ville contemporaine somptuese., LA VILLE: art et architecture en Europe - 1870-1993. Dir. Jean Dethier \& Alain Guiheux. Paris: Centre Pompidou, 1994

KONDER, Leandro. "Cidades doentes". O Globo, 9 jun. 1996, 1 Caderno, p.7.

LEFEBVRE, Henri. O direito à cidade. São Paulo: Documentos, 1969.

LEMOS, André. Cibercidades, in

unspan1.um.org/intraduc/groups/public/documents/iciepa/unpano05410.pdf (13/06/2004)

LEMOS, André (org.) Cibercidade: as cidades na cibercultura. E-papers, 2004.

Lemos, André. Cibercultura: tecnologia e vida social na cultura contemporânea. São Paulo: Sulina, 2002.

MARTÍN-BARBERO, Jesús. Dos meios às mediações: comunicação, cultura e hegemonia. 2. ed. Rio de Janeiro: Ed. UFRJ, 2002.

MARTÍN-BARBERO, Jesús. Uma agenda para a mudança de século, in Ofício do cartógrafo: travessias latino-americanas da comunicação na cultura. São Paulo: Loyola, 2004.

MIGNOLO, Walter. The many faces of cosmo-polis: border thinking and critical cosmopolitanism. In: BRECKENRIDGE, Carol A. et al. (ed.). Cosmopolitanism. Durham \& London: Duke University Press, 2002.

SANTIAGO, Silviano. O cosmopolitismo do pobre. Margens/Márgenes, Revista de Cultura, n. 2, Belo Horizonte/ Buenos Aires/ Mar Del Plata / Salvador, dez. 2002, p. 4-13..

SANTOS, Boaventura de Sousa. Cinco desafios à imaginação sociológica, in: Pela mão de Alice: o social e o político na pós-modernidade. São Paulo: Cortez, 1995.

SASSEN, Saskia. The Global City: New York, London, Tokio. Princeton: Princeton University Press, 1991. 
SCHORSKE, Carl E. La ciudad en el pensamiento europeo de Voltaire a Spengler. Punto de Vista, n. 30, Buenos Aires, jul.-oct. 1987.

SEVCENKO, Nicolau. O futuro da cidade tal como visto por Kafka do alto da Torre de Babel. Correio Braziliense, Brasília, 2 set. 1994. Suplemento Especial: III Fórum Brasília de Artes Visuais, p. 22.

SIMMEL, Georg. A metrópole e a vida mental, in VELHO, Octavio (org.). O fenômeno urbano. Rio de Janeiro: Guanabara, 1987.

TOURAINE, Alain. Critique de la modernité. Paris: Fayard, 1994. 